\title{
Preliminary investigation of thermal behaviour of PCM based latent heat thermal energy storage
}

\author{
Octavian G. Pop ${ }^{1}$, Lucian Fechete Tutunaru ${ }^{2}$, Florin Bode ${ }^{1}$ and Mugur C. Balan ${ }^{1, *}$ \\ ${ }^{1}$ Technical University of Cluj-Napoca, Dept. of Mechanical Engineering, Bd. Muncii 103-105, 400641, Cluj-Napoca, Romania \\ ${ }^{2}$ Technical University of Cluj-Napoca, Dept. of Automotive Engineering and Transports, Bd. Muncii 103-105, 400641, Cluj-Napoca, \\ Romania
}

\begin{abstract}
Solid-liquid phase change is used to accumulate and release cold in latent heat thermal energy storage (LHTES) in order to reduce energy consumption of air cooling system in buildings. The storing capacity of the LHTES depends greatly on the exterior air temperatures during the summer nights. One approach in intensifying heat transfer is by increasing the air's velocity. A LHTES was designed to be integrated in the air cooling system of a building located in Bucharest, during the month of July. This study presents a numerical investigation concerning the impact of air inlet temperatures and air velocity on the formation of solid PCM, on the cold storing capacity and energy consumption of the LHTES. The peak amount of accumulated cold is reached at different air velocities depending on air inlet temperature. For inlet temperatures of $14^{\circ} \mathrm{C}$ and $15^{\circ} \mathrm{C}$, an increase of air velocity above $50 \%$ will not lead to higher amounts of cold being stored. For Bucharest during the hottest night of the year, a $100 \%$ increase in air velocity will result in $5.02 \%$ more cold being stored, at an increase in electrical energy consumption of $25.30 \%$, when compared to the reference values.
\end{abstract}

\section{Introduction}

Worldwide effort is being dedicated to the reduction of energy consumption in the buildings sector, as about $40 \%$ of the global energy consumption is used in buildings [1]. The energy efficiency of air cooling systems can be enhanced by storing the cold available during summer nights in latent heat thermal energy storage systems (LHTES). These technologies use phase change materials (PCM), and their capability of enhancing the energy efficiency of fresh air conditioning systems have been the subject of many reviews [2-8].

Cooling applications using PCM are still in a phase where demonstration and research is required [8]. Considering that, the solidification process takes place due to the low ambient temperatures during the night the selection of the appropriate PCM plays a very important role. In [6] thermo-physical properties that the PCM must poses are presented. In [9] a selection algorithm is presented that takes into account the climatic parameters.

Organic PCM such as paraffin waxes are available on the market $[10,11]$.

Paraffin waxes are known to have a range of temperatures in which phase change occurs, and their thermo-physical properties and thermal behaviour of commercially available paraffin during solidification and melting are studied in [12-16]. Modern colorimetric techniques are necessary in order to accurately determine the variation of the heat flux with temperature during phase change. Once this variation is known, the specific heat, or apparent heat capacity variation with temperature, of the PCM can be determined, through thermal balance equations $[12,13]$.

For accumulation of maximum amount of cold, both the air inlet temperature and the air velocity present a high influence [17]. It was found that for the same flow rate and solidification time, with inlet air temperatures of (20-24) ${ }^{\circ} \mathrm{C}$ the solid mass fraction of (0.4-1) was obtained.

In [18] the melting process of a salt hydrate PCM was carried out at two different air inlet temperatures (melting temperature $+2^{\circ} \mathrm{C}$ and melting temperature $+9^{\circ} \mathrm{C}$ ) and the solid fraction in pouches was determined during melting between (0.62-1).

For this study an LHTES consisting of a packed bed of spheres with simple cubic structure, was considered. Each sphere is filled with PCM. The advantage that spherical shells have is the high ratio between the outer surface area of the sphere and the interior volume [19].

The goal of the study is to investigate the influence of the air velocity and air inlet temperature on the thermal behaviour of the LHTES and on the electrical energy consumption. For this purpose a mathematical model was developed to describe the thermal behaviour of the LHTES. The model takes into account the variation of the apparent heat capacity with temperature for the selected PCM. 


\section{Material and method}

The LHTES was designed to reduce the energy consumption of an office building situated in Bucharest, Romania at $44.511^{\circ} \mathrm{N}$ latitude, $26.078^{\circ} \mathrm{E}$ longitude and $90 \mathrm{~m}$ altitude during the month of July. The climatic data was taken from the Typical Meteorological Year (TMY) [20].

The considered office building has two floors, with surface area per floor of $1500 \mathrm{~m}^{2}$, the height of the total building is $7 \mathrm{~m}$ and the number of occupants is 180 . The specific air flow rate for this type of activity per occupant $\left(25 \mathrm{~m}^{3} / \mathrm{h} /\right.$ pers. $)$ and per unit surface area $(1.26$ $\mathrm{m}^{3} / \mathrm{h} /$ pers.) were taken from [21].

\subsection{Selection and thermal properties of the PCM}

The PCM considered for this study was adopted by implementing the selection algorithm, presented in [9], considering the particular climatic conditions of Bucharest, according to the TMY. The resulting phase change temperature is in the vicinity of $20^{\circ} \mathrm{C}$. Thus the commercially available paraffin RT20 was chosen [10].

Similar with other paraffin waxes, RT20 undergoes phase change in a temperature range. Differential scanning calorimetry (DSC), is a method that allows the determination of the thermo-physical properties of PCM, in small samples. The DSC results provide the variation of the heat flux with temperature of the PCM during melting and solidification [22], the start $\left(\mathrm{t}_{\mathrm{s}}{ }^{\circ} \mathrm{C}\right)$ and the end $\left(\mathrm{t}_{\mathrm{e}}{ }^{\circ} \mathrm{C}\right)$ temperatures of the phase change process, the onset $\left(t_{o n}\right)$ and the endset $\left(t_{\text {end }}\right)$ temperatures of the measurement, the peak temperature $\left(t_{p}{ }^{\circ} \mathrm{C}\right)$ where the value of the heat flux assumes a maximal value, and the latent heat for melting and solidification $(\mathrm{L}[\mathrm{kJ} / \mathrm{kg}])$, which represents the surface area beneath the heat flux curve.

The DSC measurements for RT20 are presented in [12], at three different cooling and heating rates. It is also specified that the cooling and heating rate of the measurement should match the rates of the application, concluding that for a rate of $0.1 \mathrm{~K} / \mathrm{min}$ the numerical predictions are the most accurate for air conditioning applications [12].

The thermal properties determined in [12] for RT20, at a cooling and heating rate of $0.1 \mathrm{~K} / \mathrm{min}$ are presented in table 1.

Table 1 thermal properties of $\mathbf{R T 2 0}$ at heating and cooling rate of $0.1 \mathrm{~K} / \mathrm{min}$

\begin{tabular}{ccccccc}
\hline \multirow{2}{*}{ Process } & $\begin{array}{c}\mathbf{t}_{\text {on }} \\
{\left[{ }^{\circ} \mathbf{C}\right]}\end{array}$ & $\begin{array}{c}\mathbf{t}_{\mathbf{s}} \\
{\left[{ }^{\circ} \mathbf{C}\right]}\end{array}$ & $\begin{array}{c}\mathbf{t}_{\mathbf{p}} \\
{\left[{ }^{\circ} \mathbf{C}\right]}\end{array}$ & $\begin{array}{c}\mathbf{t}_{\mathbf{e}} \\
{\left[{ }^{\circ} \mathbf{C}\right]}\end{array}$ & $\begin{array}{c}\mathbf{t}_{\text {end }} \\
{\left[{ }^{\circ} \mathbf{C}\right]}\end{array}$ & $\begin{array}{c}\mathbf{L} \\
{[\mathbf{k J} / \mathbf{k g}]}\end{array}$ \\
\hline Melting & 6.8 & 17.9 & 21.8 & 23 & 23.4 & 138.3 \\
Solidification & 21.8 & 21.7 & 21.5 & 21.1 & 2.9 & 143.4 \\
\hline
\end{tabular}

The density of RT20 is $880 \mathrm{~kg} / \mathrm{m} 3$ and $770 \mathrm{~kg} / \mathrm{m} 3$ in solid phase and liquid phase respectively [10].

A thermal hysteresis effect between melting and solidification is observed in the considered PCM. The thermal behaviour of the PCM during melting and solidification is not identical. There is also a slight difference between the measured latent heat, for solidification and melting. The encapsulation of the PCM also contributes to this effect [23]. This effect generates difficulties when estimating the mass fraction of solid and liquid PCM as phase change is can be interrupted in free cooling applications. To eliminate the hysteresis effect, for this study, it was assumed that the PCM behaves identically during both solidification and melting, considering a theoretical variation of the apparent heat capacity with temperature as a mean value between the apparent heat capacity for solidification and melting. Fig. 1 presents the experimentally determined variation of the apparent heat capacity with temperature for RT20 and the theoretical mean value considered.

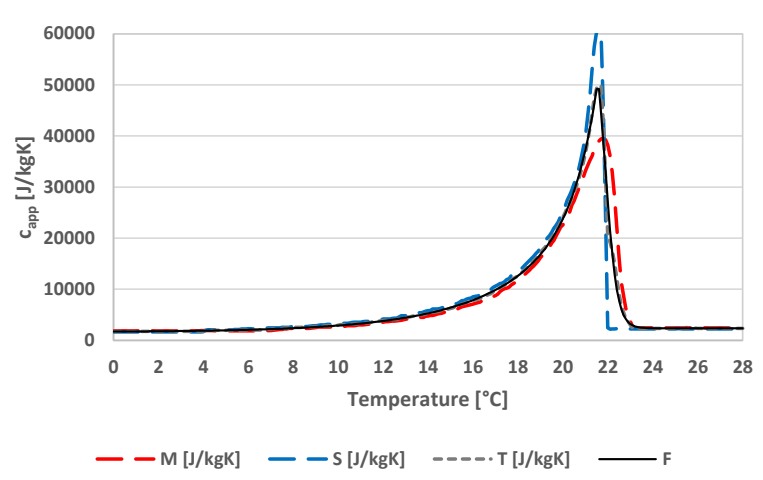

Fig. 1 The apparent heat capacity of RT20 for melting (M), solidification (S), theoretical mean value (T) and the fitted curve (F)

To take into account the variation of the apparent heat capacity with temperature in the governing thermal balance equations, a curve was fitted that accurately matches the variation. The curve is mathematically described by a discontinuous function as follows:

- An exponential growth of the second order:

$$
\begin{gathered}
c_{a p p, m}\left(t_{P C M}\right)=y_{0}+A_{1} \cdot \exp \left(t_{P C M} / b_{1}\right) \\
+A_{2} \cdot \exp \left(t_{P C M} / b_{2}\right), \text { for } t_{P C M}<t_{p}
\end{gathered}
$$

$$
\begin{aligned}
& \text { - A Boltzmann variation: } \\
& \quad c_{a p p, m}\left(t_{P C M}\right)=B_{2}+\left(B_{1}-B_{2}\right) . \\
& \cdot\left(1+\exp \left(\left(t_{P C M}-x_{0}\right) / d\right)\right), \text { for } t_{P C M} \geq t_{p}
\end{aligned}
$$

where $c_{a p p, m}\left(t_{P C M}\right)$ is the mean apparent heat capacity as a function of temperature, $t_{\mathrm{PCM}}$ is the temperature of the PCM. The values of the coefficients $A_{1}, A_{2}, B_{1}, B_{2}$, $\mathrm{b}_{1}, \mathrm{~b}_{2}, \mathrm{~d}, \mathrm{x}_{0}, \mathrm{y}_{0}$, where determined with Origin Lab, and are presented in table 2 and 3.

Table 2 Values of the coefficients -Exp. growth of the second

\begin{tabular}{lllll}
\multicolumn{5}{c}{ order: $\mathrm{t}_{\mathrm{PCM}}<\mathrm{t}_{\mathrm{p}}$} \\
\hline $\mathrm{y}_{0}$ & $\mathrm{~A}_{1}$ & $\mathrm{~A}_{2}$ & $\mathrm{~b}_{1}$ & $\mathrm{~b}_{2}$ \\
\hline 1612.07 & $4.29 \mathrm{E}-6$ & 93.27 & 0.96 & 3.81 \\
\hline
\end{tabular}

Table 3 Values of the coefficients -Boltzmann variation:

\begin{tabular}{llll}
\multicolumn{4}{c}{$\mathrm{t}_{\mathrm{PCM}}>\mathrm{t}_{\mathrm{p}}$} \\
\hline $\mathrm{B}_{1}$ & $\mathrm{~B}_{2}$ & $\mathrm{x}_{0}$ & $\mathrm{~d}$ \\
\hline 64397.50 & 2361.30 & 21.90 & 0.26 \\
\hline
\end{tabular}


The peak temperature for both solidification and melting was considered to be $21.5^{\circ} \mathrm{C}$, and the theoretical latent heat was determined with the following equation:

$$
L_{P C M, m}=\int_{t_{\text {on }}}^{t_{\text {end }}} c_{\text {app }, m}\left(t_{P C M}\right) d t
$$

where $\mathrm{L}_{\mathrm{PCM}, \mathrm{m}}$ is the mean latent heat $[\mathrm{kJ} / \mathrm{kg}]$ for both solidification and melting, assuming a value of 140,50 $\mathrm{kJ} / \mathrm{kg}$, determined considering $\mathrm{t}_{\mathrm{on}}$ and $\mathrm{t}_{\text {end }}$ at $0^{\circ} \mathrm{C}$ and $28^{\circ} \mathrm{C}$ respectively.

\subsection{The sizing of the LHTES}

A rectangular parallelepiped shape is considered for the LHTES, the spheres filled with RT20 are considered uniformly distributed inside de LHTES. The LHTES and the characteristic dimensions are presented in fig. 2 .

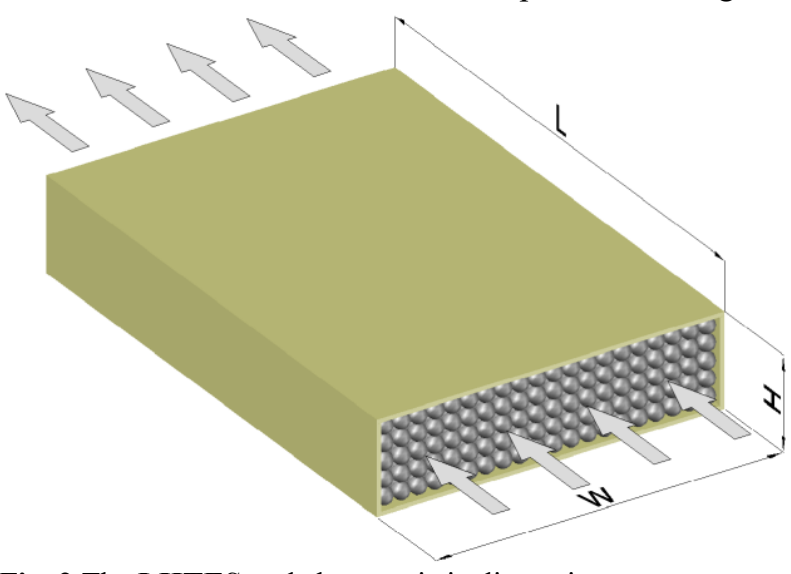

Fig. 2 The LHTES and characteristic dimensions

In figure 2, $\mathrm{H}[\mathrm{m}]$ represents the height, $\mathrm{W}[\mathrm{m}]$ represents the width and $\mathrm{L}[\mathrm{m}]$ represents the length of the LHTES. The encapsulation material is polyethylene, as in [12].

The LHTES was design based on the cooling potential of the exterior air during the nights of July, so to ensure that the mass fraction of the solid PCM after the charging period is as high as possible.

The total mass of the PCM $\left(\mathrm{m}_{\mathrm{t}, \mathrm{PCM}}[\mathrm{kg}]\right)$ for the considered LHTES was determined as:

$$
m_{t, P C M}=\frac{\dot{V}_{a} \cdot \rho_{a} \cdot c_{a} \cdot\left(t_{s, c}-t_{e x t}\right) \cdot \Delta \tau_{h}}{L}
$$

where $\dot{V}_{a}\left[\mathrm{~m}^{3} / \mathrm{s}\right]$ is the volumetric air flow rate of the air $\Delta \tau_{\mathrm{h}}=1$ hour, $\rho_{\mathrm{a}}\left[\mathrm{kg} / \mathrm{m}^{3}\right]$ is the density of the air, $\mathrm{c}_{\mathrm{a}}$ is the specific heat capacity of the air, $\mathrm{t}_{\mathrm{ext}}\left[{ }^{\circ} \mathrm{C}\right]$ is the exterior air temperature during the night, $\mathrm{t}_{\mathrm{s}, \mathrm{c}}\left[{ }^{\circ} \mathrm{C}\right]$ is the temperature at which the solidification starts. For each night of the considered period the total mass of PCM was calculated, and an average value was adopted.

\subsection{The mathematical model of the LHTES}

A mathematical model was developed in order to predict the thermal behavior of the LHTES. The governing thermal balance equations are as follows:

$$
\begin{gathered}
\dot{m}_{a} \cdot c_{a} \cdot \Delta t_{a} \cdot d \tau= \\
{\left[m_{P C M} \cdot c_{a p p, m}\left(t_{P C M}\right)+\rho_{s} \cdot V_{s} \cdot c_{s}\right] \cdot d t_{P C M}}
\end{gathered}
$$

$$
h \cdot \Delta t_{a, P C M} \cdot S_{P C M} \cdot d \tau=\dot{m}_{a} \cdot c_{a} \cdot \Delta t_{a} \cdot d \tau
$$

where $\dot{m}_{a}[\mathrm{~kg} / \mathrm{s}]$ is the mass air flow rate of the air, $\mathrm{t}_{\mathrm{a}}\left[{ }^{\circ} \mathrm{C}\right]$ is the exterior air temperature, $\mathrm{x}[\mathrm{m}]$ is the position of the row of spheres, $\tau[\mathrm{s}]$ is the time, $\mathrm{m}_{\mathrm{PCM}}$ is the mass of the PCM, $h\left[\mathrm{~W} / \mathrm{m}^{2} \mathrm{~K}\right]$ is the coefficient of forced convection, $\rho_{\mathrm{s}}\left[\mathrm{kg} / \mathrm{m}^{3}\right]$ is the density of the encapsulation material, $V_{\mathrm{s}}\left[\mathrm{m}^{3}\right]$ is the volume of the encapsulation material, $\mathrm{c}_{\mathrm{s}}[\mathrm{kJ} / \mathrm{kgK}]$ is the specific heat capacity of the encapsulation material, $\Delta \mathrm{t}_{\mathrm{a}, \mathrm{PCM}}\left[{ }^{\circ} \mathrm{C}\right.$ or $\left.\mathrm{K}\right]$ is the mean logarithmic temperature difference between the air temperature and the PCM temperature, and $\mathrm{S}_{\mathrm{PCM}}$ $\left[\mathrm{m}^{2}\right]$ is the heat transfer surface area representing the surface of the PCM spheres.

The coefficient of convection was determined as:

$$
h=\frac{N u \cdot \lambda}{d}
$$

where $\mathrm{Nu}[-]$ is the Nusselt number for forced convection over spheres, calculated with the correlation presented in $[24,25]$, as follows:

$$
N u=0.33 \cdot R e^{0.6}
$$

where $\operatorname{Re}[-]$ is the Reynolds number in the free flowing section.

This correlation is valid for a large range of $\mathrm{Re}=$ $(20 \ldots 150000)$. In the model the variation of the thermophysical properties of the air, with the temperature, was taken into account.

The following assumptions that are at the basis of the numerical solution are at the basis of the numerical solution:

- It is considered that the mass of all PCM spheres on one row is concentrated in one equivalent sphere;

- Spheres are evenly distributed, therefore porosity is constant;

- The temperature of PCM spheres from the same row is considered constant;

- Heat transfer through natural convection between the LHTES and surrounding environment is neglected;

- The air temperature on the flow section is considered constant

The same assumptions where used in [19].

The mass fraction of the solid PCM $(\gamma[-])$ was calculated as:

$$
\gamma=\frac{\int_{t_{\text {On }}}^{t_{P C M}} c_{\text {app, } m}\left(t_{P C M}\right) d t}{\int_{t_{\text {on }}}^{t_{\text {end }}} c_{\text {app }, m}\left(t_{P C M}\right) d t}
$$

\subsection{Pressure drop of the LHTES}

The local pressure drop of the LHTES $(\Delta \mathrm{p}[\mathrm{Pa}])$ was determined:

$$
\Delta p=\xi \cdot \frac{\rho_{a} \cdot w^{2}}{2}
$$

where $\mathrm{w}[\mathrm{m} / \mathrm{s}]$ is the air velocity, $\xi$ is the local pressure drop coefficient of the LHTES calculates as [26]: 


$$
\xi=\frac{1.53}{\varepsilon^{4.2}} \cdot\left(\frac{30}{R e}+\frac{3}{R e^{0.7}}+0.3\right) \cdot \frac{L}{d_{s}}
$$

where $\varepsilon$ is the porosity of the bed of spheres:

$$
\varepsilon=1-\frac{\pi}{6 \cdot(1-\cos \theta \cdot \sqrt{1+2 \cdot \cos \theta})}
$$

where $\theta=90^{\circ}$ is the angle of relative placement of the spheres [26] and $d_{s}=50 \mathrm{~mm}$ is the considered exterior diameter of the spheres. The wall thickness of the sphere is $1 \mathrm{~mm}$. The considered material from which the spheres were manufactured is polyethylene with a specific heat capacity of $\mathrm{c}_{\mathrm{s}}=1.55[\mathrm{~kJ} / \mathrm{kgK}]$ and a density of $\rho_{\mathrm{s}}=925\left[\mathrm{~kg} / \mathrm{m}^{3}\right]$ [27].

According to the TMY, the ambient air temperatures during the nights of the month of July in Bucharest are ranging from $13^{\circ} \mathrm{C}$ to $21^{\circ} \mathrm{C}$. In order to solidify as much mass as possible the convective heat transfer must be enhanced by increasing the air velocity. This however results in additional energy required for the circulation of air through the LHTES. Using the mathematical model, a numerical analysis was carried out, considering a series of constant air inlet $\left(\mathrm{t}_{\mathrm{i}}\left[{ }^{\circ} \mathrm{C}\right]\right)$ temperature in the interval of (13-21) ${ }^{\circ} \mathrm{C}$, with an increment of $1^{\circ} \mathrm{C}$. The air velocity was also increased up to $300 \%$, with a step of $25 \%$, to study both the effect on the heat transfer intensity as well as the impact on the consumed energy.

The electric energy consumed by the fan $\left(\mathrm{E}_{\mathrm{f}}[\mathrm{Wh}]\right)$ was determines as:

$$
E_{f}=\dot{V}_{a} \cdot \Delta p \cdot \tau / \eta_{v}
$$

where $\tau$ [hours] is the operating time and $\eta_{\mathrm{v}}$ is the efficiency of the fan considered 0.8 for this study.

Each numerical simulation was carried out for a time period of $5 \mathrm{~h}$, and the initial PCM temperature was considered to be $28^{\circ} \mathrm{C}$.

The LHTES sizing algorithm was implemented in $\mathrm{C}++$ and the results were exported in Excel.

\section{Results and discussions}

\subsection{The size of the LHTES}

The required air flow rate for the considered office building is $8280 \mathrm{~m}^{3} / \mathrm{h}$. The reference air velocity corresponding to this air flow rate is $0.77 \mathrm{~m} / \mathrm{s}$. The mass of the PCM integrated in the LHTES was determined using eq. (4), resulting in a total quantity if $2.065 \mathrm{t}$ of PCM. The Entire mass of PCM was distributed in the LHTES rectangular parallelepiped shaped resulting in four heat exchangers with the following dimension: $\mathrm{H}=0.50 \mathrm{~m}, \mathrm{~W}=1.50 \mathrm{~m}$ and $\mathrm{L}=2.20 \mathrm{~m}$.

During cyclic operating conditions, for air cooling application, melting of the entire mass of available PCM in the LHTES occurs, especially after peak operating conditions. Solidification of the entire mass of PCM is however problematic as after peak operating conditions the temperatures of the following night are high. As the mass, heat transfer surface area and size of the LHTES are constant parameters, the only method of intensifying the heat transfer between air and PCM is by increasing the velocity of the heat transfer fluid, in this case air.

\subsection{Influence of air inlet temperature and air velocity}

Fig. 3 and 4 present the correlation between the accumulated cold, the mass fractions of solid PCM and air velocity, for air inlet temperatures of $13^{\circ} \mathrm{C}, 17^{\circ} \mathrm{C}$ and $21^{\circ} \mathrm{C}$.
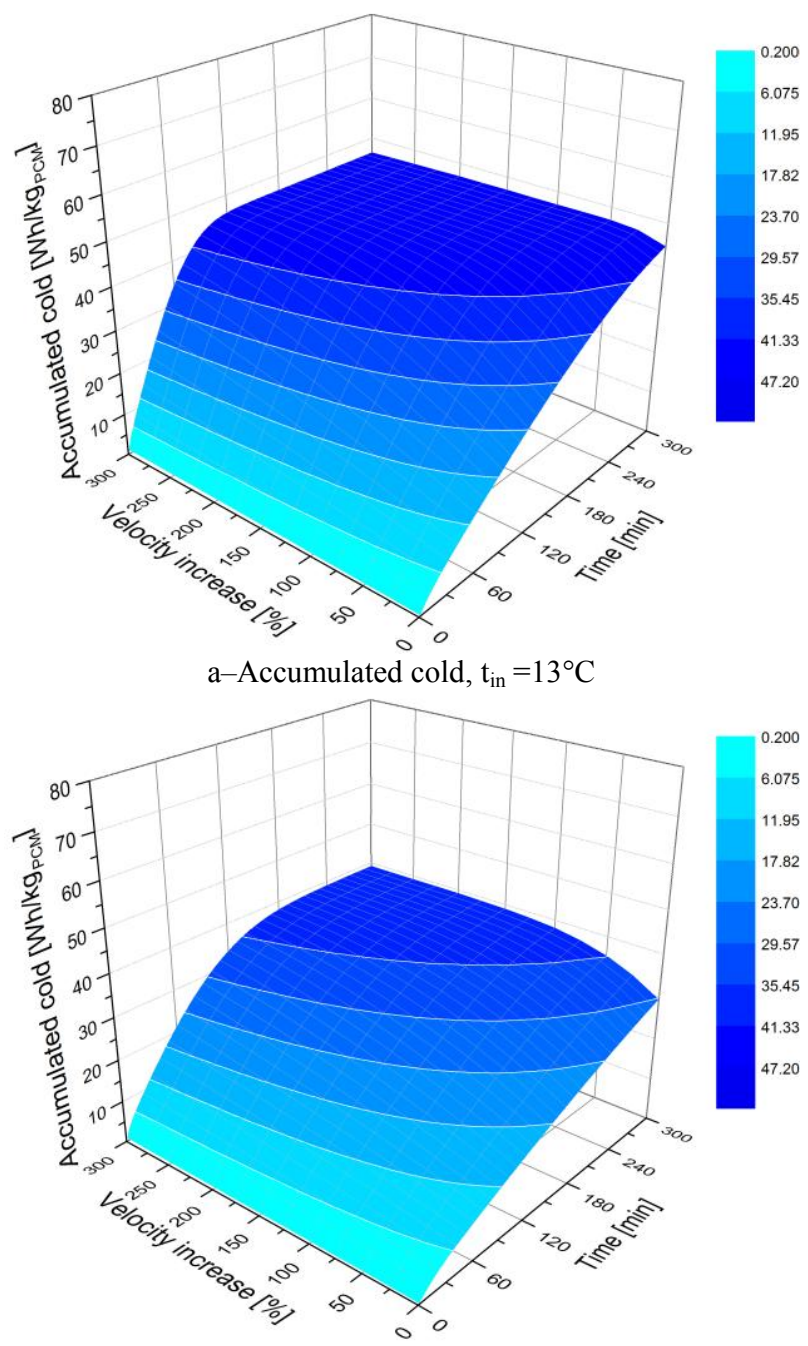

b-Accumulated cold, $\mathrm{t}_{\text {in }}=17^{\circ} \mathrm{C}$

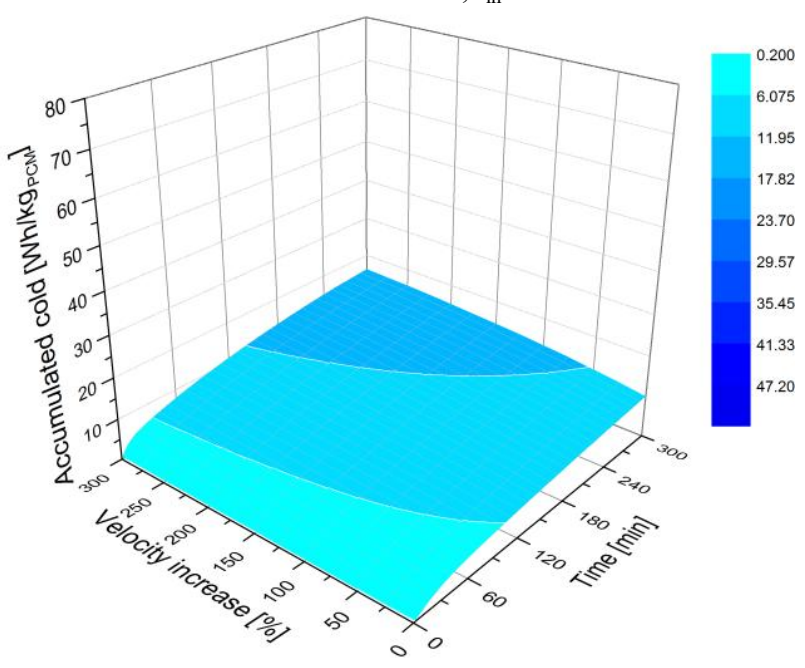

c-Accumulated cold, $\mathrm{t}_{\mathrm{in}}=21^{\circ} \mathrm{C}$

Fig. 3 Variation of accumulated cold with air velocity during 5 hours of charging 


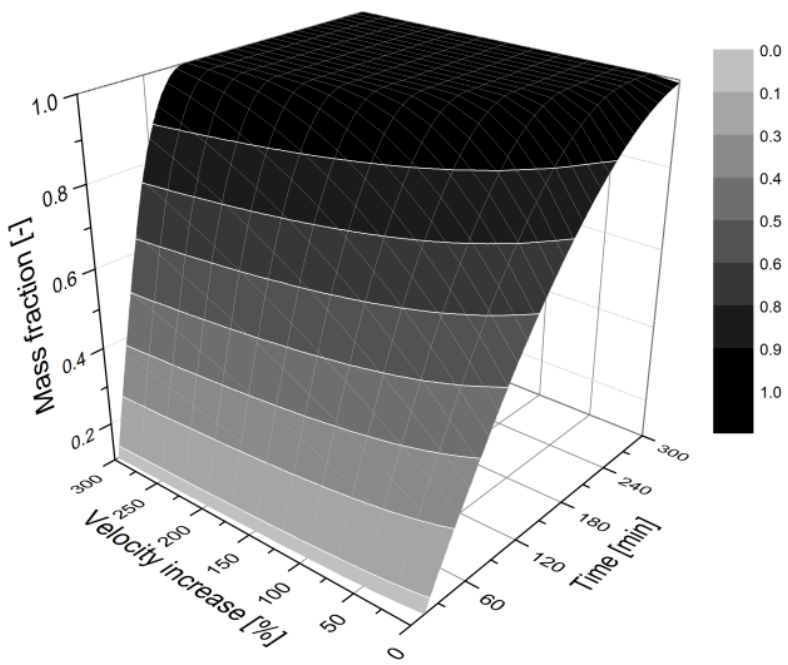

a-Mass fraction of solid PCM, $\mathrm{t}_{\text {in }}=13^{\circ} \mathrm{C}$

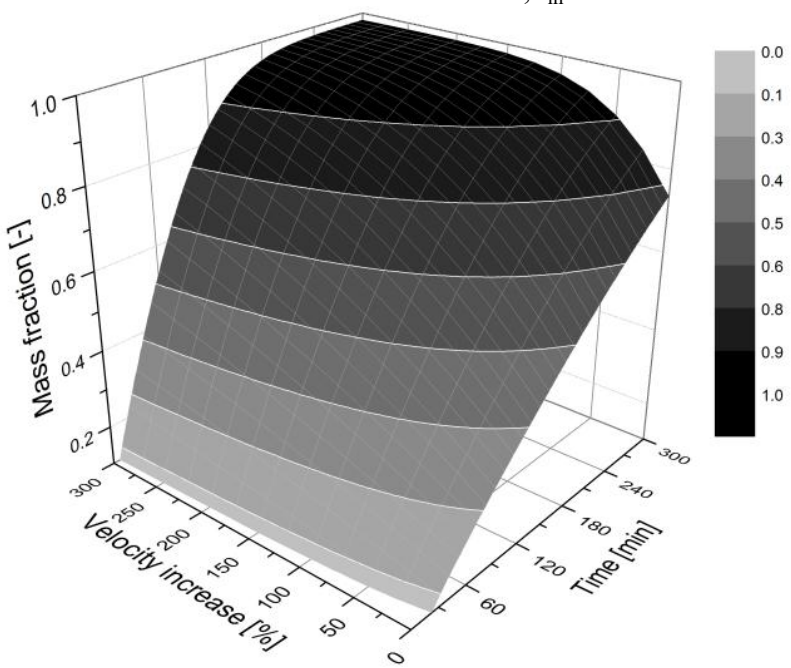

b-Mass fraction of solid PCM, $\mathrm{t}_{\text {in }}=17^{\circ} \mathrm{C}$

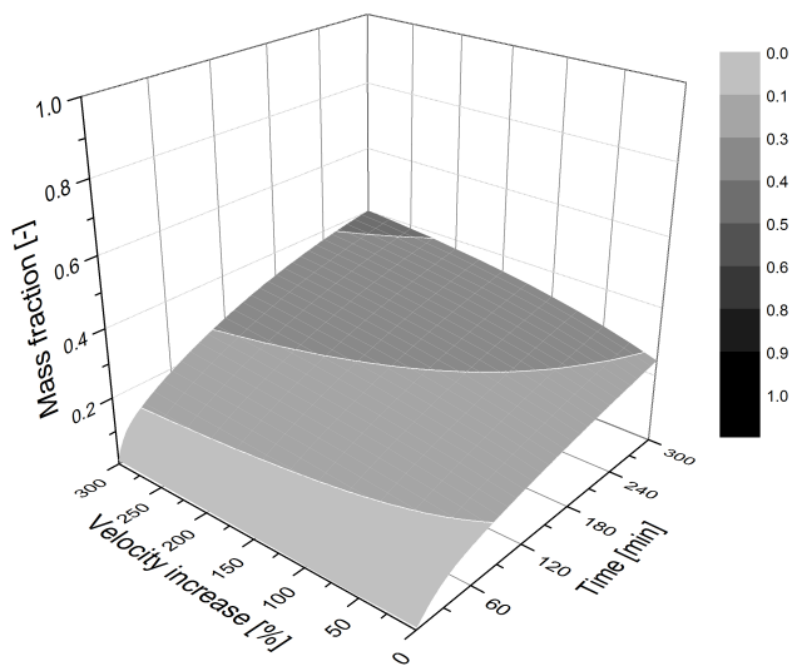

c-Mass fraction of solid $\mathbf{P C M}, \mathrm{t}_{\text {in }}=21^{\circ} \mathrm{C}$

Fig. 4 Variation of mass fraction of the solid PCM with air velocity during 5 hours of charging

The influence of air inlet temperature on the electrical energy consumed by the fan is negligible. Considering the air inlet temperature of $13^{\circ} \mathrm{C}$ as reference, at an air inlet temperature of $21^{\circ} \mathrm{C}$ the energy consumed by the fan drops with a maximum of only
$2.62 \%$. Fig. 5 presents the variation of the accumulated energy consumption of the fan at different velocities during $5 \mathrm{~h}$ of operation, for an air inlet temperature of $13^{\circ} \mathrm{C}$.

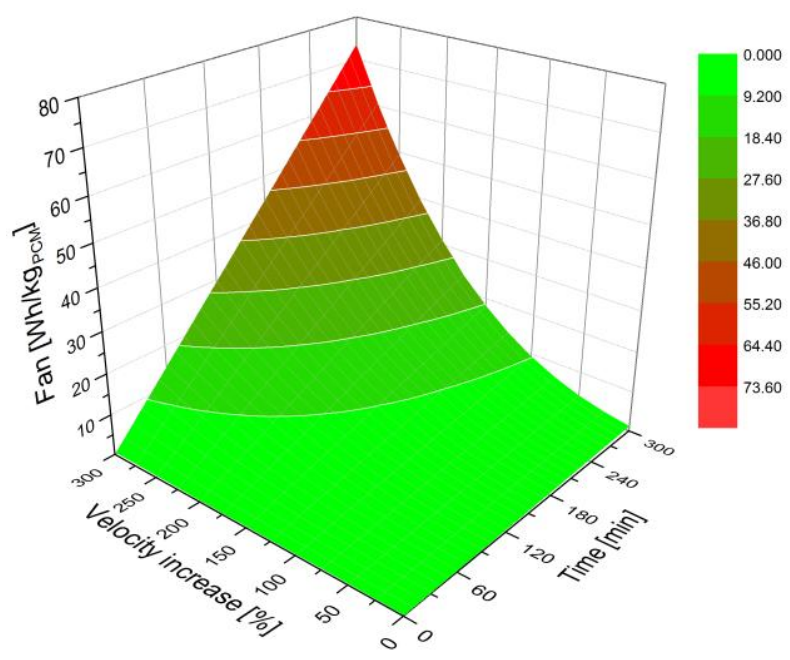

Fig. 5 The variation of electrical Energy absorbed by the Fan with air velocity during 5 hours of charging

Fig. 6 presents the total accumulated cold, at different air velocities and different air inlet temperatures, after five hours of charging. The total accumulated cold $\left[\mathrm{Wh} / \mathrm{kg}_{\mathrm{PCM}}\right]$ and the electrical energy consumed by the fan $\left[\mathrm{Wh} / \mathrm{kg}_{\mathrm{PCM}}\right]$ was calculated considering the maximum value of cold that can be stored at the studied air inlet temperature interval, velocities and charging time, as reference.

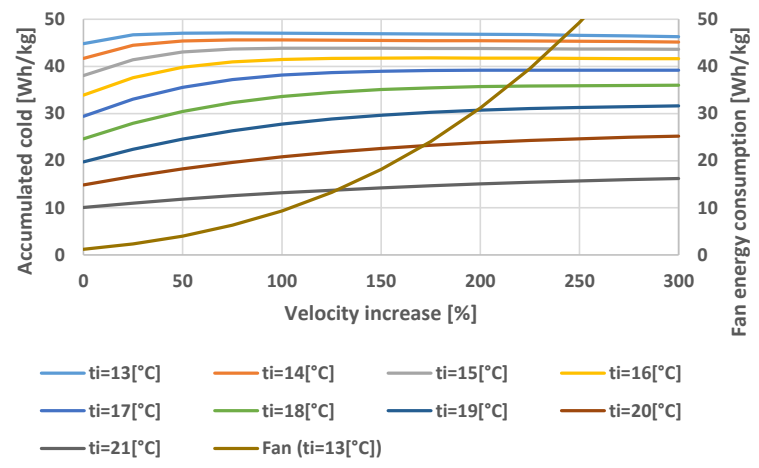

Fig. 6 Variation of accumulated cold and electrical energy consumed by the fan with air velocity, at different air inlet temperatures

The maximum value of cold that can be stored is $47.09\left[\mathrm{Wh} / \mathrm{kg}_{\mathrm{PCM}}\right]$ at an air inlet temperature of $13^{\circ} \mathrm{C}$ and air velocity of $3.067 \mathrm{~m} / \mathrm{s}$. The minimum value of cold that can be stored is $10.06\left[\mathrm{Wh} / \mathrm{kg}_{\mathrm{PCM}}\right]$ at an air inlet temperature of $21^{\circ} \mathrm{C}$ and at the reference air velocity of $0.77 \mathrm{~m} / \mathrm{s}$.

Fig. 7 shows the formation of solid mass of PCM at different air velocities and different air inlet temperature, after five hours of charging. 


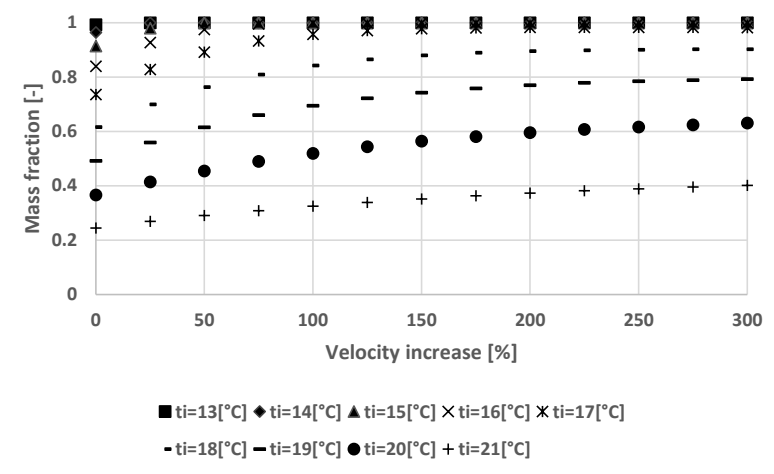

Fig. 7 Evolution of mass fraction of solid PCM with air velocity, at different air inlet temperature

A stagnation on the variation curves of accumulated cold and of solid mass fraction of PCM is observed in the following cases: for the air temperature of $13{ }^{\circ} \mathrm{C}$, above a velocity increase of $25 \%$; for the air temperature of (14-15) ${ }^{\circ} \mathrm{C}$, above a velocity increase of $50 \%$; for the air temperature of $16^{\circ} \mathrm{C}$, above a velocity increase of $100 \%$; for the air temperature of $17{ }^{\circ} \mathrm{C}$, above a velocity increase of $150 \%$.

For air inlet temperature of $18^{\circ} \mathrm{C}$ the stagnation of the variation of accumulated cold and solid mass fraction of PCM is observed at the intersection between the fan's electrical energy consumption curve and the accumulated cold curve. Above this point the fan consumes more energy than the energy stored a cold in the LHTES. An air velocity increase of maximum 50\% considering the variation of the fan's electrical energy consumption curve is a good compromise between accumulated cold, solidified mass of PCM and electrical energy consumption.

For air inlet temperatures between $(19-21){ }^{\circ} \mathrm{C}$, for the considered operating conditions, a stagnation zone in this interval is inexistent. An air velocity increase of maximum $50 \%$ considering the variation of the fan's electrical energy consumption curve is a good compromise between accumulated cold, solidified mass of PCM and electrical energy consumption.

Table 4 summarizes the variations of the accumulated cold, solid mass formed and energy consumption of the fan, determined by the variations of the inlet air temperature and velocity.

Table 4 Response of the LHTES at the variation of the inlet air temperature and velocity

\begin{tabular}{cccccc}
\hline $\mathbf{t}_{\mathbf{i}}\left[{ }^{\circ} \mathbf{C}\right]$ & $\begin{array}{c}\uparrow \mathbf{w} \\
{[\mathbf{\%}]}\end{array}$ & $\begin{array}{c}\uparrow \mathbf{Q}_{\mathbf{a}} \\
{[\mathbf{\%}]}\end{array}$ & $\begin{array}{c}\uparrow \boldsymbol{\gamma} \\
{[\mathbf{\%}]}\end{array}$ & $\begin{array}{c}\uparrow \mathbf{E}_{\mathbf{f 1}} \\
{[\mathbf{\%}]}\end{array}$ & $\begin{array}{c}\uparrow \mathbf{E}_{\mathbf{f} 2} \\
{[\mathbf{\%}]}\end{array}$ \\
\hline 13 & 25 & 4.20 & 0.69 & 92.83 & 2.50 \\
14 & 50 & 8.81 & 3.63 & 230.23 & 6.65 \\
15 & 50 & 13.18 & 9.33 & 230.19 & 7.26 \\
16 & 100 & 22.36 & 18.98 & 673.46 & 23.78 \\
17 & 150 & 32.58 & 32.83 & 1399.27 & 56.79 \\
\hline
\end{tabular}

$\uparrow E_{\mathrm{fl}}$ is the surplus electric energy consumption of the fan reported to the same value at the reference air velocity $\uparrow E_{\mathrm{f} 2}$ is the surplus electric energy consumption of the fan reported to the accumulated cold at the reference air velocity $\uparrow Q_{\mathrm{a}}$ is the increase in accumulated cold

For air inlet temperature of $16^{\circ} \mathrm{C}$, the stagnation zone starts at air velocity increase of $100 \%$, where the percentage of energy consumed by the fan and cold stored, when compared to the reference accumulated cold are very close $\left(\mathrm{Q}_{\mathrm{a}}=22.36 \%\right.$ and $\left.\mathrm{E}_{\mathrm{f} 2}=23.78 \%\right)$.

For an air inlet temperature of $17^{\circ} \mathrm{C}$, to reach the stagnation zone of the cold accumulation curve at a minimum increase in air velocity of $150 \%$, the electrical energy consumed by the fan increases with $56.79 \%$ when compared to the reference accumulated cold, while the cold stored increases with only $32.58 \%$ when compared to the reference accumulated cold.

In these cases accumulating the maximum amount of cold at the given parameters requires higher amounts of electrical energy absorbed by the fan.

For the air inlet temperature of $16^{\circ} \mathrm{C}$, an increase in air velocity of $75 \%$ will lead to $20.80 \%$ more cold being accumulated, $18.46 \%$ more solid mass being formed while the while the increase in electrical energy consumed by the fan is only $14.86 \%$, when compared to the reference accumulated cold. In this case PCM is not fully solidified, the maximum value of the solid mass fraction being 0.995 .

The same compromise can be considered for air inlet temperature of $17^{\circ} \mathrm{C}$, by reducing the increase in air velocity from $150 \%$ to $100 \%$, the resulting increase in accumulated cold is $29.79 \%$ with an increase in electrical energy consumption of $27.33 \%$, compared to the reference value, while the maximum value of the solid mass fraction is 0.957 . In these cases the stagnation zone of the cold accumulation curve is not reached, however the increase in electrical energy consumption of the LHTES is lower than the increase in stored cold.

Fig. 8 and 9 show the PCM temperature distribution and mass fraction of solid PCM distribution, in the LHTES at $17^{\circ} \mathrm{C}$ and $21^{\circ} \mathrm{C}$ and the reference air velocity and an air velocity increased by $50 \%$, after five hours of charging.

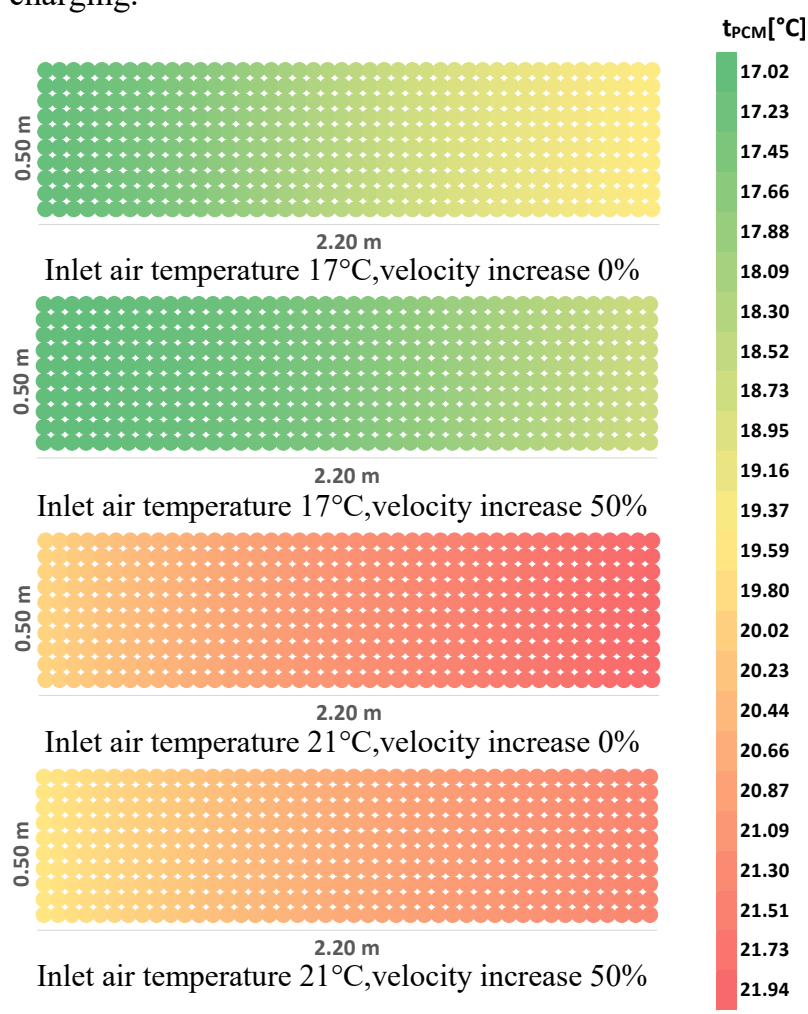

Fig. 8 The PCM Temperature distribution in the LHTES 


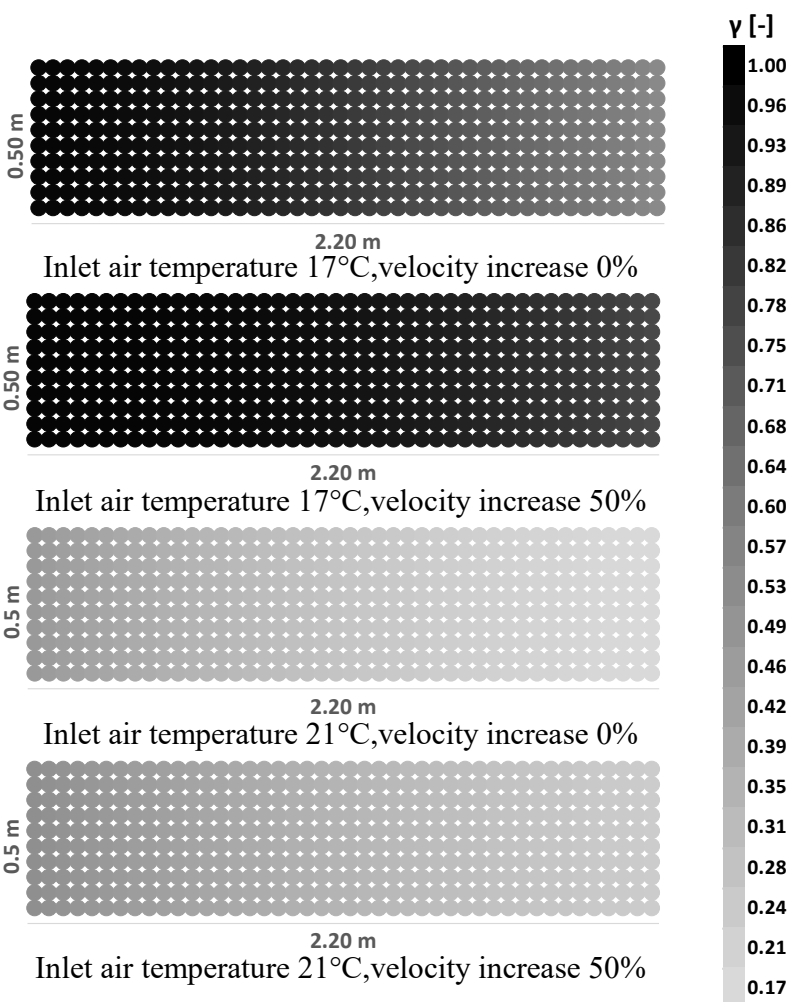

Fig. 9 The mass fraction of solid PCM distribution in the LHTES

A simulation was carried out (as a case study) for the hottest day of the year in Bucharest, according to the TMY, ( $6^{\text {th }}$ of July), representing the most unfavorable situation for the cold accumulation in the PCM. For the air inlet temperatures of $(16-19){ }^{\circ} \mathrm{C}$ the air velocity and consequently the air flow rate was increased up to $100 \%$ with an increment of $10 \%$.

Fig. 10 shows the variation of the exterior temperature over a period of $24 \mathrm{~h}$ according to the TMY and end temperature of the solidification process.

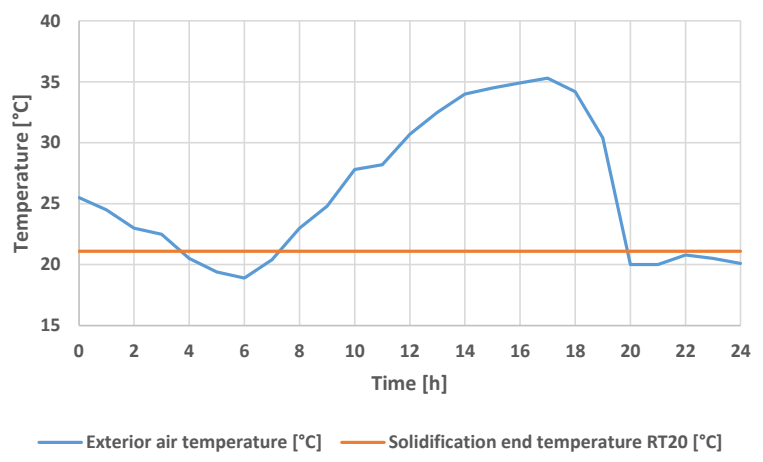

Fig. 10 Variation of the exterior air temperature during the hottest day of July according to the TMY and the PCM temperature at which solidification ends

As can be seen from fig. 10 the potential for the PCM to solidify is limited by the low ambient air temperatures during the charging period, due to the high ambient temperatures. Therefore for air inlet temperatures between (16-19) ${ }^{\circ} \mathrm{C}$ different simulations were carried out where the air velocity was increased up to $100 \%$, with an increment of $10 \%$.
Table 5 presents the influence of air velocity increase during cold accumulation for the hottest day in Bucharest ( $6^{\text {th }}$ of July) according to the TMY.

Table 5 Impact of velocity increase on the accumulated cold $\left(Q_{a}\right)$, and on the corresponding energy absorbed by the fan during cold accumulation $\left(\mathrm{E}_{\mathrm{f}}\right)$

\begin{tabular}{cccc}
\hline$\uparrow \mathbf{w}$ & $\mathbf{w}$ & $\uparrow \mathbf{Q a}$ & $\uparrow \mathbf{E}_{\mathbf{f}}$ \\
{$[\%]$} & {$[\mathrm{m} / \mathrm{s}]$} & {$[\%]$} & {$[\%]$} \\
\hline $0.0 \%$ & 0.77 & $0.00 \%$ & $0.00 \%$ \\
$10.0 \%$ & 0.84 & $0.54 \%$ & $1.23 \%$ \\
$20.0 \%$ & 0.92 & $1.06 \%$ & $2.69 \%$ \\
$30.0 \%$ & 1.00 & $1.58 \%$ & $4.41 \%$ \\
$40.0 \%$ & 1.07 & $2.09 \%$ & $6.42 \%$ \\
$50.0 \%$ & 1.15 & $2.59 \%$ & $8.72 \%$ \\
$60.0 \%$ & 1.23 & $3.09 \%$ & $11.35 \%$ \\
$70.0 \%$ & 1.30 & $3.57 \%$ & $14.32 \%$ \\
$80.0 \%$ & 1.38 & $4.05 \%$ & $17.66 \%$ \\
$90.0 \%$ & 1.46 & $4.56 \%$ & $21.17 \%$ \\
$100.0 \%$ & 1.53 & $5.02 \%$ & $25.30 \%$ \\
\hline
\end{tabular}

It can be observed that by increasing the air velocity up to $100 \%$ when compared to the reference air velocity, the accumulated cod can be increased up to $5.02 \%$ with a supplementary energy consumption of the fan of $25.3 \%$. These values correspond to an increase of accumulated cold of $59.86 \mathrm{Wh} / \mathrm{kg}$ from $57.00 \mathrm{Wh} / \mathrm{kg}$ at the reference velocity and an increase of fan energy consumption of $8.89 \mathrm{Wh} / \mathrm{kg}$ from $7.10 \mathrm{Wh} / \mathrm{kg}$ at the reference velocity.

\section{Conclusions}

This article presents a numerical analysis of thermal behavior of LHTES using RT20 a commercially available paraffin wax as PCM.

The thermal behavior of the LHTES was analyzed at different air inlet temperatures and air velocities. The air velocities were increased up to $300 \%$ with an increment of $25 \%$. The studied temperature domain was (13-21) ${ }^{\circ} \mathrm{C}$.

It was observed that at certain values of the air velocity the variation of the cold stored in the LHTES stagnate. The stagnation zone starts at an increase in air velocity of: $25 \%$ for air inlet temperature of $13^{\circ} \mathrm{C}, 50 \%$ for air inlet temperature of $14^{\circ} \mathrm{C}$ and $15^{\circ} \mathrm{C}, 100 \%$ for air inlet temperature of $16^{\circ} \mathrm{C}$ and $150 \%$ for air inlet temperature of $17^{\circ} \mathrm{C}$. For the temperature interval of $(18$ 21) ${ }^{\circ} \mathrm{C}$ the stagnation zone is not clearly defined.

The impact on the formation of solid mass of PCM and the fan's electrical energy consumption was also investigated.

The numerical investigation identified values of the air velocity where the amount of cold stored in the LHTES reaches peak values for certain temperatures.

The study evaluated the favorable impact of the inlet air temperature on the accumulated cold that increase with $346 \%$ from $10.05 \mathrm{Wh} / \mathrm{kg}$ at the inlet air temperature of $21{ }^{\circ} \mathrm{C}$ to $44.82 \mathrm{Wh} / \mathrm{kg}$ at the inlet air temperature of $13{ }^{\circ} \mathrm{C}$, and reference air velocity. 
Following the study it was highlighted that a reasonable increase of the air velocity between (25-100) $\%$, depending on air inlet temperatures, determines a benefic impact on the accumulated cold. For the air inlet temperature of $15{ }^{\circ} \mathrm{C}$ the amount of accumulated cold solidified mass of PCM increases with $13.18 \%$ and $9.33 \%$ respectively, while the increase in energy consumption of the fan represents $7.26 \%$ of the accumulated cold at the reference velocity.

The numerical simulation carried out for the hottest day of July in Bucharest, revealed that the accumulated cold can be increased by $5.02 \%$ with an increase in electrical energy consumption of the fan by $25.30 \%$. Due to the low air velocities $(0.77-1.53) \mathrm{m} / \mathrm{s}$ the electrical energy consumed by the fan is relatively low in comparison to the accumulated cold. To store 59.86 $\mathrm{Wh} / \mathrm{kg}$ of cold in the LHTES $8.89 \mathrm{Wh} / \mathrm{kg}$ of electrical energy is required, representing $14.91 \%$ energy from the total accumulated cold.

With higher quantities of cold stored in the LHTES the operating hours of classic air cooling system can be reduced.

These results must be correlated with the operating hours and energy consumption of chiller which will be the subject of future research activities.

The results presented in this paper were obtained with the support of the Technical University of Cluj-Napoca through the research Contract no. 2013/12.07.2017, Internal Competition CICDI-2017.

\section{References}

1. Directive 2010/31/EU of the European Parliament and of the Council of 19 May 2010 on the energy performance of buildings 2010.

2. V.A.A. Raj, R. Velraj, Renewable and Sustainable Energy Reviews, 14, 2010

3. F.A. Regin, S.C. Solanki, J.S. Saini, Renewable and Sustainable Energy Reviews, 12, 2008

4. R. Parameshwaran, S. Kalaiselvam, S. Harikrishnan, A. Elayaperumal, Renewable and Sustainable Energy Reviews, 16, 2012

5. V. Basecq, G. Michaux, C. Inard, P. Blondeau, Advances in Building Energy Research, 7, 2013

6. E. Osterman, V.V. Tyagi, V. Butala, N.A. Rahim, U.Stritih, Energy and Buildings, 49, 2012

7. H. Akeiber, P. Nejat, M.Z.A. Majid, M.A. Wahid, F. Jomehzadeh, I.Z. Famileh, J.K. Calautit, B.R. Hughes, S.A. Zaki, Renewable and Sustainable Energy Reviews, 60, 2016

8. M. Alizadeh, S.M. Sadrameli, Renewable and Sustainable Energy Reviews, 58, 2016

9. O. Pop, M.C. Balan, Termotehnica, 12016

10. www.rubitherm.de

11. www.pcmproducts.net

12. C. Arkar, S. Medved, Thermochimica Acta, 438, 2005

13. M. Iten, S. Liu, A. Shukla, P.D. Silva, Applied Thermal Engineering, 117, 2017
14. X. Jin, H. Hu, X. Shi, X. Zhang, Energy Conversion and Management, 106, 2015

15. C. Barreneche, A. Solé, L. Miró, I. Martorell, A.I. Fernández, L.F. Cabeza, Thermochimica Acta, 553 2013

16. L. Huang, C. Doetsch, C. Pollerberg, International Journal of Refrigeration, 33, 2010

17. A. Waqas, S. Kumar, Energy and Buildings, 43, 2011

18. A. Lazaro, P. Dolado, J.M. Marín, B. Zalba, Energy Conversion and Management, 50, 2009

19. O. Pop, L.F. Tutunaru, M. Balan, Energy Procedia, 112, 2017

20. MRDPA (Ministry of Regional Development and Public Administration). "Typical meteorological data for Bucharest.” (2013) Bucharest, Romania (in Romanian)

21. Normativ pentru proiectarea, executarea si exploatarea instalatiilor de ventilare si climatizare, Indicativ I5. 2010 (in Romanian)

22. A. Hasan, S.J. McCormack, M.J. Huang, B. Norton, Energy Conversion and Management, 81, 2014

23. K. Kumarasamy, J. An, J. Yang, E.-H. Yang, Energy, 132, 2017

24. E. Cao, Heat transfer in process engineering, ed. T.M.-H. Companies, 2010

25. N. Leonăchescu, Termotehnică, ed. E.d.ș.p. București, 1981 (in Romanian)

26. I.E. Idelcik, Editura tehnică 1984 (in Romanian)

27. http://www.firebid.umd.edu/material-database.php 